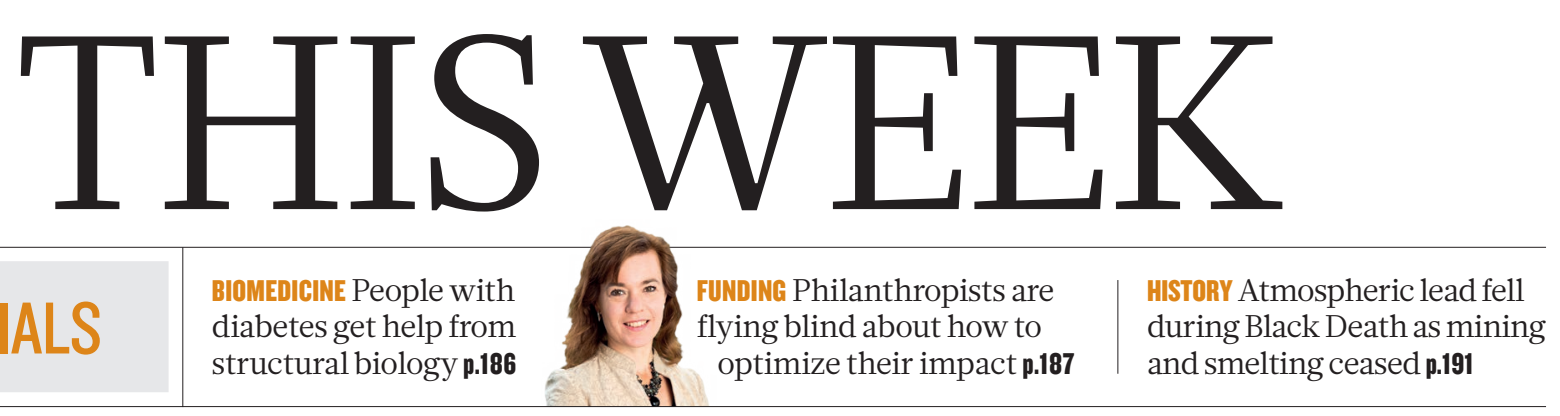

EDITORIALS

diabetes get help from structural biology p.186 flying blind about how to

optimize their impact $\mathbf{p . 1 8 7}$ during Black Death as mining and smelting ceased $\mathbf{p} .191$

\title{
On the pill
}

\section{A notable anniversary highlights the progress and benefits of contraceptives, and the continuing struggle for access to them.}

S ixty years ago, the US Food and Drug Administration approved a treatment for menstrual disturbance. Data showed that it prevented pregnancy too, but that use was taboo. Three years passed before doctors could prescribe it as a contraceptive. And another decade went by until many women could get it before marriage. By then, the drug was considered a miracle and was already famous enough to be known simply as the pill.

In 2015, the contraceptive-drug market was worth more than US $\$ 6.1$ billion globally, according to a report by Global Market Insights. And the pill has transformed society, or at least those societies in which most women have access to the drug. Epidemiologists have shown how contraceptives led to a rise in education and earnings for women in the United States and Western Europe. For example, a 2007 report analysed data from the 1960s and 1970s, and found that college enrolment in the United States was 17\% higher among women from states in which the pill was prescribed at 18 than among women from states that withheld permission until 21. And along with basic education, the pill has slowed population growth, a trend that can be linked to economic and environmental gains. In 1970, women in Bangladesh had an average of seven children; today they have two.

Large gaps in access remain, driven by sexism, poverty and cultural taboos. In South Africa, contraceptives have long been legal, but young women complain that nurses at reproductive-health-care clinics shame them for asking about sex. Three times more teenage girls have children in South Africa than in the United Kingdom (4.4\% compared with $1.4 \%)$. HIV rates in South Africa are the highest in the world, and the regions with high HIV tend to be those with high teen pregnancies.

Time and again, history shows how shame merely forces behaviour underground. HIV researchers know this, which is why labs running trials on treatments to prevent the disease offer reproductive health care as well. For this reason, they have voiced concerns over US President Donald Trump's 'gag rule', which reinstates a policy whereby US funds cannot go to any organization working abroad that discusses abortion (government funds have never been permitted for abortion itself). Salim Abdool Karim, director of the Durban-based South African AIDS research centre CAPRISA, points out that the centre now risks losing research funds from the US National Institutes of Health if a nurse at one of its satellite clinics merely addresses an HIV study participant's query on an unwanted pregnancy.

The Trump administration is poised to take direct aim at contraceptives in other ways. Proposed budget cuts to the Department of State and the United States Agency for International Development slash funds for services providing contraceptives for women in developing nations by $\$ 523$ million. A report from the Guttmacher Institute, a reproductivehealth think tank in Washington DC, estimates that, for every \$10-million drop in family-planning funds, 433,000 fewer women will receive contraceptives, which will result in 128,000 more unintended pregnancies. Studies have shown that a portion of these result in abortion,

which can be lethal to the women in places where abortion is illegal or inaccessible. A 2011 study posted on the Bulletin of the World Health Organization showed how the gag policy increased abortions when it was enacted in 2001 under president George W. Bush. The authors compared data between 1994 and 2008 from countries in sub-Saharan Africa that were receiving a high amount of US funding for reproductive health care with those receiving none. They found that abortion remained stable during this time in the latter countries, and rose

"In 1970, women in Bangladesh had an average of seven children; today they have two." sharply after 2001 in countries where funds had been cut.

Political battles and stigma have always accompanied the pill, yet the drug has stumbled towards progress over the decades. This year, a small company named Cadence moved forward with large studies to test whether women follow instructions on oral-contraceptive packs such that these might be sold over the counter. Both the American Medical Association and the American Congress of Obstetricians and Gynecologists support the measure.

A century ago, nurse Margaret Sanger fled the United States after being charged with obscenity for spreading information on birth control. In the Netherlands, she was inspired by a birth-control clinic and returned home to start her own. Later, she founded Planned Parenthood. She might be dismayed to know that millions of women still have no access to contraceptives because of a lack of political will. Or maybe she would be celebrating, because times for many other women have surely changed for the better.

\section{Line of beauty}

\section{The strange behaviour of $\mathrm{B}$ mesons may hold clues to what lies beyond the standard model.}

$\mathrm{T}$ The world's most powerful particle accelerator, the Large Hadron Collider (LHC), works incredibly well, but the next rung of understanding still seems to be just out of reach. Grasping it looks increasingly like a game of patience and precision, rather than just jumping higher. An effort to explore rare decays of 'beauty' particles is among the most promising lines of enquiry.

Researchers are desperate to unravel physics beyond the standard model, a description of particles and their interactions. Developed in the 1970s to unify three of the four fundamental forces, the standard model is concise enough to fit on a mug, and its predictions have been verified with dizzying precision. That culminated in the 2012 